\title{
Dynamics of soil properties and fungal community structure in continuous-cropped alfalfa fields in Northeast China
}

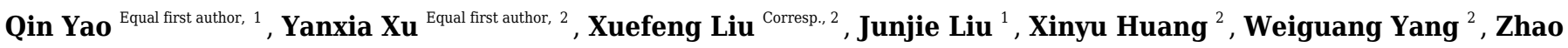 \\ Yang $^{2}$, Lan Lan ${ }^{2}$, Jingming Zhou ${ }^{2}$, Guanghua Wang ${ }^{\text {Corresp. } 1}$ \\ ${ }^{1}$ Key Laboratory of Mollisols Agroecology, Northeast Institute of Geography and Agroecology, Chinese Academy of Sciences, Harbin, China \\ 2 Heilongjiang Province Institute of Animal Science, Qiqihar, China \\ Corresponding Authors: Xuefeng Liu, Guanghua Wang \\ Email address: Ixf.888888@163.com, wanggh@iga.ac.cn
}

To compensate for the seasonal imbalance between livestock and forage yield in the cold region of Northeast China, alfalfa (Medicago sativa L.) continuous cropping has been widely employed in animal husbandry. However, the effects of continuous cropping of alfalfa on soil properties, including physical, chemical and biological properties, are poorly understood. In this study, we investigated the soil properties and fungal community composition of alfalfa fields under continuous cropping for different time periods (i.e., 1, 2, $6,9,12,13$ and 35 years). The results showed that soil moisture, total $\mathrm{C}$, total $\mathrm{N}, \mathrm{NO}_{3}-\mathrm{N}$ and available $\mathrm{K}$ content decreased at less than 10 years of continuous cropping and then increased at more than 10 years of continuous cropping, but soil total $P$ and available $P$ content showed the opposite tendency. The soil fungal community composition determined using Illumina Miseq sequencing showed that continuous cropping increased the fungal alpha diversity and changed the fungal community structure. The relative abundances of Guehomyces and Chaetomium decreased, but the relative abundances of Phaeomycocentrospora and Paecilomyces increased with continuous cropping time. In addition, continuous cropping of alfalfa increased the relative abundances of some plant pathogens, such as Haematonectria haematococca and Cyphellophora sp. Soil total P and available $\mathrm{P}$ content were important soil factors affecting the soil fungal community diversity, fungal community structure and the relative abundances of specific fungi in this alfalfa continuous cropping system. 
1 Title: Dynamics of soil properties and fungal community structure in continuous-cropped alfalfa

2 fields in Northeast China

3 Author names: Qin $\mathrm{Yao}^{1, \dagger}$, Yanxia $\mathrm{Xu}^{2, \dagger}$, Xuefeng Liu ${ }^{2 *}$, Junjie Liu ${ }^{1}$, Xinyu Huang ${ }^{2}$, Weiguang

4 Yang $^{2}$, Zhao Yang ${ }^{2}$, Lan Lan ${ }^{2}$, Jingming Zhou ${ }^{2}$, Guanghua Wang ${ }^{1 *}$

5 Affiliation:

6 1. Key Laboratory of Mollisols Agroecology, Northeast Institute of Geography and Agroecology,

7 Chinese Academy of Sciences, Harbin 150081, China

8 2. Heilongjiang Province Institute of Animal Science, Qiqihar 161005, China

$9 \dagger$ These authors contributed equally to this work

11 * Corresponding author:

12 Guanghua Wang

13 No.138 Haping Road, Harbin, Heilongjiang, 150081, China

14 E-mail address: wanggh@iga.ac.cn

15 Xuefeng Liu

16 No.2 Heyi Road, Qiqihar, Heilongjiang, 161005, China

17 E-mail address: 1xf.888888@163.com 
23 Abstract: To compensate for the seasonal imbalance between livestock and forage yield in the cold region of Northeast China, alfalfa (Medicago sativa L.) continuous cropping has been widely employed in animal husbandry. However, the effects of continuous cropping of alfalfa on soil properties, including physical, chemical and biological properties, are poorly understood. In this study, we investigated the soil properties and fungal community composition of alfalfa fields under continuous cropping for different time periods (i.e., 1, 2, 6, 9, 12, 13 and 35 years). The results showed that soil moisture, total $\mathrm{C}$, total $\mathrm{N}, \mathrm{NO}_{3}^{-}-\mathrm{N}$ and available $\mathrm{K}$ content decreased at less than 10 years of continuous cropping and then increased at more than 10 years of continuous cropping, but soil total $\mathrm{P}$ and available $\mathrm{P}$ content showed the opposite tendency. The soil fungal community composition determined using Illumina Miseq sequencing showed that continuous cropping increased the fungal alpha diversity and changed the fungal community structure. The relative abundances of Guehomyces and Chaetomium decreased, but the relative abundances of

Phaeomycocentrospora and Paecilomyces increased with continuous cropping time. In addition, continuous cropping of alfalfa increased the relative abundances of some plant pathogens, such as Haematonectria haematococca and Cyphellophora sp. Soil total P and available P content were important soil factors affecting the soil fungal community diversity, fungal community structure and the relative abundances of specific fungi in this alfalfa continuous cropping system.

\section{Introduction}


Alfalfa (Medicago sativa L.), as an important perennial herbaceous forage legume, is widely grown in many countries (Raiesi, 2007; Su, 2007; Li \& Huang, 2008; Bagavathiannan, Gulden \& Van Acker, 2011) with a great contribution to the development of agriculture and animal husbandry (Han, Jia \& Wang, 2005). In China, alfalfa is cultivated in more than $4 \times 10^{6}$ hectares every year and is mainly planted in the arid and semiarid regions of northern China (Zhang et al., 2016). Northeast China is an ecotone system between agriculture and animal husbandry, and winter in this region is longer than in other parts of China (Chen et al., 2013). Thus, the animal fodder in this area nearly exclusively relies on pasture in summer and on silage in winter $(\mathrm{Su}$, 2007). Alfalfa could eliminate the seasonal imbalance between livestock and forage yield in

Northeast China due to its great yield potential, high nutritional value and wide adaptation (Chen et al., 2013). Therefore, to meet forage demand in the winter season and then enhance the productivity of livestock, a large area of alfalfa was planted continuously in Northeast China (Dong et al., 2003).

optimal length of the alfalfa growth phase is 9 years (Jiang et al., 2007). These studies also indicated that the soil quality of alfalfa fields changed with increasing age and is reflected in alfalfa productivity (Jiang et al., 2007; Ren et al., 2011). Soil quality, including physical, chemical and biological properties, can directly or indirectly influence soil productivity and 
environmental security (Doran \& Parkin, 1994). Dong et al. (2016) found that the amounts of soil organic carbon, total nitrogen, total phosphorus and available phosphorus were significantly increased when new alfalfa land was reclaimed from native sandy steppe. A pot experiment also indicated that planting alfalfa significantly increased the contents of soil organic matter, total nitrogen, available nitrogen, available phosphorus and available potassium (Luo et al., 2018). However, a long-term survey showed that the contents of soil organic carbon, total nitrogen, available phosphorus and soil nitrate nitrogen decreased within 10 years of continuous cropping of alfalfa but then increased after alfalfa grew for more than 10 years (Jiang et al., 2007).

Soil microorganisms are important components of soil ecosystems, play a critical role in material cycling (Lupwayi et al., 2004; Bastida et al., 2017), and quickly respond to changes in soil physicochemical properties (Jiang et al., 2007; Xiao et al., 2017). However, studies related to soil microbial characteristics in alfalfa fields have been limited (Beauregard et al., 2010; Zhong et al., 2012; Luo et al., 2018). Jiang et al. (2007) investigated the soil microbial properties under alfalfa continuous cropping fields in the Loess Plateau of China and found that soil microbial biomass and soil basal respiration decreased steadily from 3 years of alfalfa continuous cropping to 9 years but increased from 15 years to 25 years. Luo et al. (2018) assessed the influence of alfalfa revegetation on the soil microbial community in an Entisol of East China and found that alfalfa revegetation significantly increased soil microbial diversity (e.g., OTU richness and Shannon index) and affected the soil microbial community structures through changes in soil physicochemical properties. In addition to the continuous growth of alfalfa, continuous cropping of soybean caused the gradual transformation of soil from 'bacterial type' to 'fungal type', as 
84

85

continuous cropping enhances fungal growth while inhibits bacterial proliferation (Jie, Liu \& Cai, 2013). In particular, the abundance of pathogenic fungi, which could influence plant growth and crop yield, was increased with continuous cropping (Guo et al., 2011; Bai et al., 2015).

Therefore, considering the change in soil microorganisms (especially fungi or pathogenic fungi), to support the sustainable development of animal husbandry in Northeast China, it is necessary to reveal the relationships between soil quality and long-term continuous cropping of alfalfa. In this study, soil samples were collected from continuous-cropped alfalfa fields of different cropping times in Northeast China, and the soil properties and fungal communities were investigated. The objectives of this study were 1) to assess the dynamic changes in soil properties and fungal community structures with continuous cropping time and 2) to estimate the comprehensive relationships among soil properties, soil fungal communities and continuous cropping time.

\section{Materials and Methods}

2.1 Study site and experimental design

The research fields were set up in an experimental field of the Heilongjiang Province Institute of Animal Science, which is located in the Fularji district $\left(47^{\circ} 15^{\prime} \mathrm{N}, 123^{\circ} 41^{\prime} \mathrm{E}\right)$, Qiqihar, Heilongjiang Province, China. The average annual temperature is $3{ }^{\circ} \mathrm{C}$, and the average annual precipitation is $450 \mathrm{~mm}$ in this area. The soil is aeolian sandy soil, the $\mathrm{pH}$ value of the soil is 7.4 and the salinity is $0.24 \%$. 
104 Fields with alfalfa continuous cropping for 1, 2, 6, 9, 12, 13 and 35 years were selected for this

105

106

study, which were encoded ACC1y, ACC2y, ACC6y, ACC9y, ACC12y, ACC13y and ACC35y, respectively. All the treatments were randomly arranged in a large experimental field, and each treatment covered more than $900 \mathrm{~m}^{2}$ in area. At the beginning of the established experiment, alfalfa (Medicago sativa L.cv. Longmu801) was seeded at a density of 3,000,000 seeds ha-1. Chemical compound fertilizer $\left(\mathrm{N} 16 \%, \mathrm{P}_{2} \mathrm{O}_{5} 16 \%, \mathrm{~K}_{2} \mathrm{O} 16 \%\right)$ was annually applied at $280 \mathrm{~kg} \mathrm{ha}^{-}$ ${ }^{1}$ in each experimental plot in late May. The alfalfa fields were managed with conventional cultivation techniques without grazing. The alfalfa was mowed to the soil surface twice and removed from the field in June and August every year except in the first year when the alfalfa was seeded. At other times of year, the alfalfa grew freely.

2.2 Soil sampling and soil property determination

The soil samples were collected at a soil depth of $0-15 \mathrm{~cm}$ on 25 June 2015 when the alfalfa was blooming. Each soil sample was a mixture of more than 5 individual soil cores collected from an area of $300 \mathrm{~m}^{2}$ (one-third of the total area) of each treatment. A total of 21 soil samples were obtained from seven continuous cropping alfalfa fields. The soil samples were sieved through a $2 \mathrm{~mm}$ mesh to thoroughly homogenize them, and the visible plant roots, residues and stones were manually removed. All samples were transferred to the laboratory in an ice-cooled box and divided into two groups: one was placed into a $50 \mathrm{~mL}$ centrifuge tube and kept at $-80{ }^{\circ} \mathrm{C}$ for soil DNA analysis, and the other was dried in the room for determination of soil properties, except for ammonium nitrogen and nitrate nitrogen, which were tested with fresh soil. 
124 For the measurement of soil basic properties, we adopted the methods described in our 125 previous paper (Yao et al., 2017). Briefly, the soil $\mathrm{pH}$ was determined using a $\mathrm{pH}$ meter in a soil

126

128 water suspension $(1: 2.5 \mathrm{w} / \mathrm{v})$. The soil moisture content was measured gravimetrically by drying $15 \mathrm{~g}$ of fresh soil to a constant weight in a drying oven at $105^{\circ} \mathrm{C}$ for $12 \mathrm{~h}$. The soil total carbon (TC) and total nitrogen (TN) contents were measured using an elemental analyzer (VarioEL III, Germany) (Jones \& Willett, 2006). Soil total phosphorus (TP) digested with $\mathrm{H}_{2} \mathrm{SO}_{4}-\mathrm{HClO}_{4}$, available phosphorus (AP) extracted with $0.5 \mathrm{M} \mathrm{NaHCO}_{3}$, and ammonium nitrogen $\left(\mathrm{NH}_{4}{ }^{+}-\mathrm{N}\right)$ and nitrate nitrogen $\left(\mathrm{NO}_{3}^{-}-\mathrm{N}\right)$ extracted with $2.0 \mathrm{M} \mathrm{KCl}$ were assayed using a continuous flow analytical system (SKALAR SAN ${ }^{++}$, The Netherlands) (Miranda, Espey \& Wink, 2001). Soil total potassium (TK) digested with $\mathrm{HNO}_{3}-\mathrm{HClO}_{4}-\mathrm{HF}$ and available potassium (AK) extracted with $1.0 \mathrm{M} \mathrm{CH}_{3} \mathrm{COONH}_{4}$ were quantified using inductively coupled plasma-atomic emission spectrometry (ICPS-7500, Shimadzu, Japan) (Lu, 1999).

\subsection{Soil DNA extraction, PCR amplification and Illumina MiSeq sequencing}

Soil DNA was extracted from the frozen soil samples ( $0.5 \mathrm{~g}$ wet weight $)$ using a Fast $\mathrm{DNA}^{\circledR}$ Spin Kit for Soil (MP Biomedicals, Santa Ana, CA, USA) according to the manufacturer's instructions and diluted in DES buffer (DNA Elution Solution-Ultra Pure Water). After DNA extraction, the fungal ITS rRNA was amplified using the primers ITS1F/ITS2R (White et al., 1990), with the forward primer modified with a unique $6 \mathrm{nt}$ barcode at the 5 ' end. PCRs were performed using $25 \mu \mathrm{L}$ PCR mixture containing $0.5 \mu \mathrm{L}$ of each primer at $10 \mu \mathrm{M}, 1.0 \mu \mathrm{L}$ of template DNA (10 ng), and $23 \mu \mathrm{L}$ of Platinum PCR SuperMix (TransGen Biotech Co. Ltd., Beijing, China). The amplification was performed at $94{ }^{\circ} \mathrm{C}$ for $3 \mathrm{~min}$, followed by 35 cycles at 
$14594{ }^{\circ} \mathrm{C}$ for $30 \mathrm{~s}, 55^{\circ} \mathrm{C}$ for $30 \mathrm{~s}$, and $72{ }^{\circ} \mathrm{C}$ for $30 \mathrm{~s}$, followed by an extension at $72{ }^{\circ} \mathrm{C}$ for $10 \mathrm{~min}$

146 (Liu et al., 2015). Each sample was amplified for three technical replicates. The PCR products

147 were checked in a $1.5 \%$ agarose gel with the Gold View ${ }^{\mathrm{TM}}$ nucleic acid stain (Beijing Solarbio

148 Science \& Technology Co. Ltd., Beijing, China) and were then purified using the agarose gel

149 DNA purification kit (Takara, Dalian, China). The amplicons from all samples were normalized

150 to equimolar amounts and were sequenced using the Illumina MiSeq platform at the Shanghai

151 Majorbio Biotechnology Company, Shanghai, China.

152 2.4 Processing of fungal ITS sequencing data

153 The raw sequence data obtained from Illumina MiSeq sequencing were processed and analyzed using QIIME Pipeline Version 1.8.0 (http://qiime.org/tutorials/tutorial.html) (Caporaso et al., 2010). Briefly, low-quality sequences with a quality score $<20$ and shorter than 200 bp in length were removed. Chimeric sequences were detected and eliminated using the Uchime algorithm (Edgar et al., 2011). The remaining high-quality sequences were clustered into Operational Taxonomic Units (OTUs) at 97\% similarity using USEARCH (Edgar, 2010). The representative sequence of OTUs was aligned using the Python Nearest Alignment Space Termination (PyNAST) (DeSantis et al., 2006; Caporaso et al., 2010) with a phylogenetic tree built using Fast Tree (Price, Dehal \& Arkin, 2009). The taxonomic classification of each representative OTU was assigned using a BLAST comparison against sequences within the

163 GenBank database. In order to analyze the fungal communities at the same sequencing depth, the lowest sequencing number of 29000 sequences was randomly selected per sample. All sequences have been deposited in GenBank with accession number PRJNA509700. 
166

167

168

169

170

171

172

173

174

175

176

177

178

179

180

181

182

183

184

185

186

\subsection{Statistical analysis}

The Chao1 richness, Shannon index, Simpson index and Phylogenetic diversity were calculated in QIIME and used to compare the fungal alpha diversity among treatments. Significant differences in soil parameters, fungal alpha diversity and the fungal relative abundances of different taxonomic levels among treatments were determined by one-way analysis of variance (ANOVA), and the correlations between fungal relative abundances and soil parameters and continuous cropping years were tested by Pearson's correlation analysis using SPSS software (Version 22.0). Nonmetric multidimensional scaling (NMDS) analysis was performed to compare the fungal beta diversity between treatments, and canonical correspondence analysis (CCA) was conducted to determine which soil parameters were most frequently related to fungal communities. The NMDS and CCA analyses were all conducted using the "vegan" package in the R environment (R v.2.8.1) (R Development Core Team, 2006).

The fungal OTU taxonomic information was uploaded to FUNGuild (http://www.stbates.org/guilds/app.php) for functional prediction (Nguyen et al., 2016).

\section{Results}

\subsection{Soil physicochemical properties}

The variations in soil physicochemical properties are displayed in Table 1. Overall, soil moisture, $\mathrm{TC}, \mathrm{TN}, \mathrm{NO}_{3}^{-}-\mathrm{N}$ and $\mathrm{AK}$ contents decreased with the extending time from 1 year to 9 years and then increased from 9 years to 35 years in continuous cropping alfalfa soils (Table 1). In contrast, the contents of TP and AP increased and decreased with cropping years in the 
187 188 189

treatments of less and more than 10 years, respectively. The soil $\mathrm{pH}$ value and $\mathrm{TK}$ content fluctuated with the cropping year. The ammonium nitrogen content $\left(\mathrm{NH}_{4}{ }^{+}-\mathrm{N}\right)$ did not significantly change under alfalfa continuous cropping fields.

\subsection{Fungal community composition}

In total, 792,738 high-quality sequences were obtained from all soil samples, ranging from 29,798 to 44,636 per soil sample $($ mean $=37749)($ Table 2$)$. When grouped at the $97 \%$ similarity level, 1911 different phylotypes (OTUs) were obtained across all soil samples, with a mean of 653 phylotypes per soil sample.

The phyla Ascomycota, Zygomycota and Basidiomycota were dominant fungi with relative abundances ranging from $64.37 \%$ to $76.15 \%$, from $8.61 \%$ to $17.98 \%$ and from $6.47 \%$ to $15.45 \%$ across all samples, respectively (Fig. 1; Table S1). The relative abundance of Ascomycota was significantly and negatively correlated with TC, whereas it was positively correlated with TK. Basidiomycota was significantly and negatively correlated with $\mathrm{pH}$, whereas it was positively correlated with TP and AP. However, Zygomycota was significantly and positively correlated with TC, whereas it was negatively correlated with TP and AP (Table S2).

At the class level, Sordariomycetes was dominant, with a relative abundance of more than $30 \%$ across all samples. In addition, two classes, Tremellomycetes and Dothideomycetes, were less abundant (relative abundance $>10 \%$ in at least one sample) (Table S3), and they had positive or negative correlations with soil $\mathrm{pH}, \mathrm{TC}, \mathrm{TP}$ and continuous cropping year (Table S2).

More than 60 fungal orders were detected across all samples. Among them, Hypocreales, Mortierellales, Sordariales and Pleosporales were abundant orders, with a relative abundance of 
208

209

210

211

212

213

214

215

216

217

218

219

220

221

222

223

224

225

226

227

228

more than 5\% (Table S4). The relative abundance of the most abundant order, Hypocreales, which belongs to the Sordariomycetes class of Ascomycota, was positively and negatively correlated with cropping year and TP, respectively, while the order Sordariales had the opposite correlations (Table S2 and S4).

More than 300 fungal genera were detected across all samples. Among them, 38 abundant fungal genera (relative abundance $>0.3 \%$ ) accounted for more than $80 \%$ of the fungal sequences (Table S5). Guehomyces and Mortierella were dominant genera, and their relative abundances varied from $0.42 \%$ to $17.19 \%$ and $8.42 \%$ to $16.74 \%$, respectively (Table S5). The relative abundance of Guehomyces was positively correlated with soil TP and AP but negatively correlated with soil $\mathrm{pH}$ and alfalfa continuous cropping year $(\mathrm{r}=-0.595, P=0.004)$ (Table S2, Fig. 2A). The relative abundance of Mortierella was negatively correlated with soil TP and AP but positively correlated with soil TC (Table S2). In addition, the relative abundances of three less abundant genera, Chaetomium $(\mathrm{r}=-0.645, P=0.002)$, Phaeomycocentrospora $(\mathrm{r}=0.864, P$ $<0.0001)$ and Paecilomyces $(\mathrm{r}=0.839, P<0.0001)$, were negatively and positively correlated with alfalfa continuous cropping year, respectively (Table S2, Fig. 2B-D), and they also had significant correlations with some soil properties, such as soil $\mathrm{pH}, \mathrm{TN}, \mathrm{TP}, \mathrm{AP}$ and AK (Table S2).

3.3 Fungal functional groups

Among the 1911 OTUs detected in this study, 866 OTUs (45.32\% of the total OTUs) were annotated to 14 functional groups based on the FUNGuild database (Fig. 3, Table S6). The relative abundances of plant pathogens and plant saprotrophs were significantly different 
229

230

231

232

233

234

235

236

237

238

239

240

241

242

243

244

245

246

247

248

249

between the alfalfa continuous cropping treatments of less than and more than 10 years, except for some treatments (Table S6). In addition, the highest abundance of fungal parasites appeared in ACC9y (1.12\%) (Table S6).

Eighty-four OTUs were assigned as the functional group of plant pathogen (Table S6). Among them, the top 6 OTUs belonged to the phylum Ascomycota, with relative abundances ranging from $0.01 \%$ to $2.62 \%$ (Fig. 4 , Table S7). Of these, the relative abundances of OTU211 (Haematonectria haematococca) and OTU1311 (Cyphellophora sp.) under continuous cropping alfalfa for more than 10 years were significantly higher than those under continuous cropping for less than 10 years (Fig. 4C, F). Their abundances were positively correlated with soil TN and continuous cropping year and negatively correlated with soil TP and AP (Table S7). The relative abundances of OTU1176 (Fusarium incarnatum) in ACC13y and ACC35y were significantly higher than that in other treatments (Fig. 4B). OTU1176 abundance had a negative correlation with soil TP and a positive correlation with soil $\mathrm{NO}_{3}{ }^{-}-\mathrm{N}, \mathrm{AK}$ and alfalfa continuous cropping year (Table S7). However, the relative abundances of the other three dominant OTUs (OTU1786, OTU1880 and OTU1028) did not change regularly with continuous cropping year (Fig. 4A, D, E), but they had significant correlations with some soil properties, such as soil $\mathrm{pH}$, TN and AK (Table S7).

$3.4 \alpha$-diversity pattern of soil fungal communities

To compare the $\alpha$-diversity of soil fungal communities, the same survey effort level of 29,000 sequences was randomly selected from each sample. The coverage values of all the samples were more than $99 \%$ (Table 2), indicating that the current sequencing depth was sufficient to capture 
250 the fungal diversity. The number of phylotypes ranged from 555 to 746 , and phylogenetic

251 diversity ranged from 216 to 300 across all soil samples (Table 2). Pairwise analysis showed that

252 both phylotype richness $(\mathrm{r}=0.780, P<0.0001)$ and phylogenetic diversity $(\mathrm{r}=0.731, P<$

253 0.0001) of the soil fungal community increased with the cropping years (Fig. 5A, B). Among soil

254 properties, the soil TP and AP contents were significantly and negatively correlated with both the

255 phylotype richness and phylogenetic diversity (Fig. 5C-F). In addition, other $\alpha$-diversity indices,

256 Chao1 richness, Shannon index and Simpson index, also differed among different treatments

257 (Table 2).

$258 \quad 3.5 \beta$-diversity pattern of soil fungal communities

259 Based on Bray-Curtis distance dissimilarity, the $\beta$-diversity of the fungal communities was 260 evaluated with NMDS analysis (Fig. 6A). The NMDS plot exhibited the best separation of fungal

261 communities of alfalfa continuous cropping for less than 10 years from those for more than 10

262 years, and thus all samples were separated into two major groups (Fig. 6A). A similar result was

263 also found by the clustering analysis (Fig. 1). Within each group, the fungal communities under

264 alfalfa continuous cropping for less than or more than 10 years were not well separated.

265 A CCA plot was employed to identify the major soil variables that affected the fungal

266 community structure. Based on the results of the Mantel test (Table S8), soil parameters

267 significantly correlated with the fungal community structure were selected for the CCA analysis

268 (Fig. 6B). Of all the tested soil variables, soil TP $(\mathrm{r}=0.463, P=0.001)$ had the longest arrow

269 along the CCA1 axis, which indicated that soil TP was the most important soil parameter in

270 shifting the soil fungal communities. The second most important soil factor was soil AP $(\mathrm{r}=$ 
271

272

273

274

275

276

277

278

279

280

281

282

283

284

285

286

287

288

289

290

291

0.399, $P=0.001)$ (Fig. 6B, Table S8). In addition, soil $\mathrm{pH}(\mathrm{r}=0.175, P=0.020)$ also made an important contribution to the change in soil fungal community structure (Fig. 6B, Table S8).

\section{Discussion}

4.1 Variation in soil properties under alfalfa continuous cropping

Soil properties are influenced by long-term planting or continuous cropping (Fu et al., 2017;

Chen et al., 2018). In this study, alfalfa continuous cropping resulted in a change in soil properties in the arid Songnen Plain of Northeast China (Table 1). The soil moisture, TC, TN and $\mathrm{NO}_{3}^{-}-\mathrm{N}$ contents first decreased and then increased with the extension of cultivation years. This result is consistent with the report of Jiang et al. (2007), who found that these soil parameters under alfalfa continuous cropping fields, which were influenced by nutrient uptake and litter input to soil, decreased with the greater amount of dry alfalfa grass removed from the field from 3 years to 9 years, while the soil parameters increased from 15 years to 25 years in the semiarid Loess Plateau of Northwest China. In addition, the contents of soil TP and AP in our study increased with planting years under short-term alfalfa continuous cropping conditions ( $<10$ years) (Table 1). This result was basically consistent with the finding of Dong et al. (2016), who stated that the soil TP and AP contents in alfalfa soils increased significantly after applying fertilizer in a short-term period in the Heihe River Basin of an arid region of Northwest China. In addition, the soil AP content in the treatments of alfalfa continuous cropping for less than 10 years was significantly higher than that in the treatments of continuous cropping for more than 10 years.

This result was also found in a long-term investigation by Fan et al. (2011), who reported that 
292 after alfalfa grew for more than 10 years, harvesting of the alfalfa with higher density removed

293 more phosphorus and returned less plant residue to soil, resulting in a decrease in soil AP content

294 in the Loess Plateau of northern China. In short, alfalfa continuous cropping led to changes in

295 soil properties, and 10 years may be the optimal length for the alfalfa continuous cropping

296 system in view of soil quality.

4.2 Variation in soil fungal community composition under alfalfa continuous cropping

In our study, we found that Ascomycota, Zygomycota and Basidiomycota were the dominant

phyla, while Chytridiomycota was a minor phylum across all soil samples (Fig. 1, Table S1). A similar result was also reported in a Panax notoginseng continuous cropping field (Tan et al., 2017), suggesting that Ascomycota, Zygomycota and Basidiomycota are abundant fungal phyla in continuous cropping systems. In addition, continuous cropping significantly elevated and reduced the relative abundances of Ascomycota and Basidiomycota, respectively, especially compared to their abundances in ACC1y (Table S1). This result is basically consistent with the report of Luo et al. (2018), who found that planting alfalfa significantly changed the soil properties (e.g., pH, TC, TP and AP) for microbial growth and subsequently increased the relative abundance of Ascomycota and reduced that of Basidiomycota in alfalfa fields in eastern

China.

At the genus level, the relative abundance of Chaetomium decreased with the extension of continuous cropping time (Fig. 2B). Chaetomium belongs to Ascomycota and has the ability to degrade cellulose with efficient cellobiose dehydrogenase activity (Harreither et al., 2011;

312 Abdelkader \& Hamed, 2013). Moreover, Chaetomium was reported as a potential biocontrol 
313 agent that can resist some soil-borne pathogens by producing antifungal compounds (Huang et

314 al., 2016). Meng et al. (2018) found that the abundance of the pathogen Fusarium oxysporum

315 was negatively correlated with the relative abundance of the antagonist Chaetomium. The

316 decrease in the relative abundance of Chaetomium in our study indicated that alfalfa continuous

317 cropping may suppress the growth of antagonistic fungi. In addition, we observed that the

318 relative abundance of Paecilomyces increased with prolonged alfalfa continuous cropping time

319 (Fig. 2D) and had a positive correlation with soil moisture (Table S2). This result was consistent

320 with that in a previous study by Mackie et al. (1999), who stated that dry conditions could

321 restrict the expression of fungal disease, in view of the many species in the genus Paecilomyces

322 that are pathogens (Israel et al., 2018; Piekarska, Trusz \& Szczesniak, 2018). Meanwhile, some

323 species of this genus were demonstrated as biocontrol agents, such as Paecilomyces lilacinus

324 (Wei et al., 2015; Abd-Elgawad \& Askary, 2018) and Paecilomyces fumosoroseus (Ruiu, 2018).

325 Furthermore, some species of Paecilomyces could cause food contamination and spoilage (Ismail,

326 2001) as well as play an important role in soil carbon turnover (Kluczek-Turpeinen et al., 2007).

327 We also found that the relative abundance of Paecilomyces in alfalfa soils was positively

328 correlated with soil $\mathrm{TN}$ and AK content and negatively correlated with soil TP and AP content

329 (Table S2). These soil properties were significantly influenced by alfalfa continuous cropping

330 (Table 1). In this case, the genus Paecilomyces of Ascomycetes has a complex role in the

331 environment, and our future study should be deeply focused on its role in the alfalfa continuous

332 cropping system.

Peer] reviewing PDF | (2019:01:33998:2:1:NEW 3 May 2019) 
FUNGuild analysis, and the relative abundance of plant pathogens increased with the extension of the alfalfa continuous cropping time (Fig. 3, Table S6). This result was consistent with the findings of Li et al. (2014), who stated that continuous cropping increased the abundance of pathogenic fungi in peanut soil. Similarly, the abundances of soil-borne pathogens were increased in continuous cropping fields of cucumber (Feng et al., 2016), tomato (Fu et al., 2017) and potato (Liu et al., 2014). These findings suggested that the environmental conditions under long-term continuous cropping were likely to be prone to pathogen proliferation. In particular, we found that the relative abundance of OTU211, which was assigned to Haematonectria haematococca of Ascomycota phylum, was significantly increased when the alfalfa continuous cropping time was longer than 10 years (Fig. 4C). Haematonectria haematococca is a plant pathogen, and its teleomorph is Fusarium solani, which is virulent and causes alfalfa root rot (Li, Li \& Meng, 2005; Cao et al., 2008; Kong et al., 2018). Moreover, the relative abundance of OTU211 (Haematonectria haematococca) had significant correlations with soil moisture, TN, TP, AP and AK (Table S7), indicating that alfalfa continuous cropping may cause the occurrence of root rot that influenced the alfalfa growth indirectly through the changes in soil edaphic properties. In addition, the relative abundance of OTU1311, which was assigned to Cyphellophora sp., was also significantly higher in the treatments with continuous cropping for more than 10 years than that in the treatments of less than 10 years (Fig. 4F). Some species of the fungal genus Cyphellophora are potential pathogens (Decock et al., 2003; Ma et al., 2018), and 
354 as soil TC, TN, TP and AP (Table S7), suggesting that continuous cropping may promote the

355 proliferation of pathogens (Guo et al., 2011; Ranzi et al., 2017).

3564.3 Variation in soil fungal diversity under alfalfa continuous cropping

357 Previous studies showed that the taxonomic richness and diversity of soil microorganisms

358 were strongly influenced by continuous cropping (Jie, Liu \& Cai, 2013; Li et al., 2014; Bainard

359 et al., 2017; Tan et al., 2017). In our study, we observed that the number of phylotypes and the

360 phylogenetic diversity were significantly increased with continuous cropping time (Table 2; Fig.

$3615 \mathrm{~A}, \mathrm{~B}$ ), which was consistent with a previous report in cropping wheat field soils (Bainard et al.,

362 2017). Similarly, a study in soybean fields of Northeast China indicated that continuous cropping

363 increased the fungal community diversity (Bai et al., 2015). However, soil fungal community

364 diversity in a long-term experiment of monoculture soybean detected by DGGE pattern was not

365 significantly influenced by continuous cropping (Li et al., 2010). The discrepancy may be mainly

366 due to the sensitivity and limitations of the molecular methods (Bai et al., 2015). In addition, the

367 soil fungal community diversity in our study was negatively correlated with soil TP and AP

368 contents (Fig. 5C-F), which were significantly influenced by continuous cropping (Table 2),

369 indicating that continuous cropping could indirectly affect the soil fungal community diversity

370 by changing the soil properties.

3714.4 Variation in soil fungal community structure under alfalfa continuous cropping

372 In this study, alfalfa continuous cropping significantly changed the soil fungal community

373 structure (Fig. 6A). This result agreed with the findings of Bai et al. (2015), who stated that the

374 fungal community structure in soybean soils was influenced by continuous cropping using 454

Peer] reviewing PDF | (2019:01:33998:2:1:NEW 3 May 2019) 
375 high-throughput sequencing analysis. Similarly, Song et al. (2018) found that changes in soil

376 nutrients and $\mathrm{pH}$ caused by the continuous cropping of Coptis chinensis affected fungal survival

377 and growth, thereby significantly altered fungal community composition. In addition, the

378 communities under continuous cropping for more than 10 years were obviously different from

379 those of less than 10 years (Fig. 6A), indicating that 10 years may be a cut-off point in the

380 variation of soil fungal communities under alfalfa continuous cropping. Moreover, the structure

381 of the microbial community could also be altered by soil properties (Yao, Jiao \& Wu, 2006;

382 Pulleman et al., 2012; Tan et al., 2017; Chen et al., 2018). In this study, the CCA plot showed

383 that soil $\mathrm{pH}, \mathrm{TP}$ and AP were the dominant factors in shifting the soil fungal community

384 structure in continuous cropping alfalfa fields (Fig. 6B). Similar results were also reported by

385 Song et al. (2018), who stated that some soil properties, such as soil pH and AP, displayed

386 significant effects on the fungal community composition. These soil properties in our study were

387 markedly influenced by continuous cropping (Table 1), indicating that continuous cropping

388 altered soil characteristics and then changed soil fungal community structure (Tan et al., 2017).

\section{Conclusions}

391 In summary, long-term continuous cropping of alfalfa altered the soil properties and soil

392 fungal community structure and increased the soil fungal alpha diversity. In particular, alfalfa

393 continuous cropping influenced the relative abundances of some plant pathogens, such as

394 Haematonectria haematococca and Cyphellophora sp. The soil TP and AP contents, which were

395 significantly affected by alfalfa continuous cropping, were not only negatively correlated with 
396 soil fungal community diversity but also significantly correlated with soil fungal community

397 structure and the relative abundance of specific fungi at the different classification levels. In the

398 end, we suspected that the optimal length of alfalfa continuous cropping may be approximately

39910 years according to the variation in soil basic properties and soil fungal community 400 composition, and the further isolation and identification of plant pathogens detected in this study 401 will be required in future research.

402

\section{References}

Abd-Elgawad M, Askary TH. 2018. Fungal and bacterial nematicides in integrated nematode management strategies. Egyptian Journal of Biological Pest Control 28:74 DOI: 10.1186/s41938-018-0080-X.

407

Abdelkader S, Hamed M. 2013. In vitro studies on wood degradation in soil by soft-rot fungi: Aspergillus niger and Penicillium chrysogenum. International Biodeterioration \& Biodegradation 78:98-102 DOI: 10.1016/j.ibiod.2012.12.013.

Bagavathiannan MV, Gulden RH, Van Acker RC. 2011. Occurrence of alfalfa (Medicago sativa L.) populations along roadsides in southern Manitoba, Canada and their potential role in intraspecific gene flow. Transgenic Research 20:397-407 DOI: 10.1007/s11248-010-94252.

Bai L, Cui JQ, Jie WG, Cai BY. 2015. Analysis of the community compositions of rhizosphere fungi in soybeans continuous cropping fields. Microbiological Research 180:49-56 DOI: 10.1016/j.micres.2015.07.007. 
417 Bainard LD, Navarro-Borrell A, Hamel C, Braun K, Hanson K, Gan Y. 2017. Increasing the 418 frequency of pulses in crop rotations reduces soil fungal diversity and increases the Environment 240:206-214 DOI: 10.1016/j.agee.2017.02.020.

421

422

423

424

425

426

427

428

429

430

431

432

433

434

435

proportion of fungal pathotrophs in a semiarid agroecosystem. Agriculture Ecosystems \&

Bastida F, Torres IF, Andrésabellán M, Baldrian P, Lópezmondéjar R, V`etrovský T, Richnow HH, Starke R, Ondoño S, García C. 2017. Differential sensitivity of total and active soil microbial communities to drought and forest management. Global Change Biology 23(10):4185-4203 DOI: 10.1111/gcb.13790.

Beauregard MS, Hamel C, Atul-Nayyar, Starnaud M. 2010. Long-term phosphorus fertilization impacts soil fungal and bacterial diversity but not am fungal community in alfalfa. Microbial Ecology 59(2):379-389 DOI: 10.1007/s00248-009-9583-z.

Cao LX, Zhao CH, Bai QJ, Shao ZZ. 2008. Identification of the pathogens causing root rot of alfalfa in Inner Mongolia. Acta Agriculturae Boreali-Sinica, 23(6):105-107 (In Chinese).

Caporaso JG, Kuczynski J, Stombaugh J, Bittinger K, Bushman FD, Costello EK, Fierer N, Pena AG, Goodrich JK, Gordon JI, Huttley GA, Kelley ST, Knights D, Koenig JE, Ley RE, Lozupone CA, McDonald D, Muegge BD, Pirrung M, Reeder J, Sevinsky JR, Tumbaugh PJ, Walters WA, Widmann J, Yatsunenko T, Zaneveld J, Knight R. 2010. QIIME allows analysis of high-throughput community sequencing data. Nature Methods 7:335-336 DOI: 10.1038/nmeth.f.303.

Peer) reviewing PDF | (2019:01:33998:2:1:NEW 3 May 2019) 
436 Chen JS, Gao C, Di GL, Zhu RF, Zhang YX. 2013. Effects of cutting on alfalfa yield and quality

437 in northeast china. Journal of Animal \& Veterinary Advances 12(2):253-260 DOI: 10.3923/javaa.2013.253.260.

439

440

441

442

443

444

445

446

447

448

449

450

451

452

453

454

455

456

Chen W, Teng Y, Li Z, Liu W, Ren W, Luo Y, Christie P. 2018. Mechanisms by which organic fertilizer and effective microbes mitigate peanut continuous cropping yield constraints in a red soil of south china. Applied Soil Ecology 128:23-34 DOI: 10.1016/j.apsoil.2018.03.018.

Decock C., Delgado-Rodríguez G, Buchet S, Seng JM. 2003. A new species and three new combinations in Cyphellophora, with a note on the taxonomic affinities of the genus, and its relation to Kumbhamaya and Pseudomicrodochium. Antonie van Leeuwenhoek 84(3): 209216 DOI: 10.1023/A:1026015031851.

DeSantis Jr TZ, Hugenholtz P, Keller K, Brodie EL, Larsen N, Piceno YM, Phan R, Andersen GL. 2006. NAST, a multiple sequence alignment server for comparative analysis of $16 \mathrm{~S}$ rRNA genes. Nucleic Acids Research 34:394-399 DOI: 10.1093/nar/gk1244.

Dong SK, Long RJ, Hu ZZ, Kang MY, Pu XP. 2003. Productivity and nutritive value of some cultivated perennial grasses and mixtures in the alpine region of the Tibetan Plateau. Grass \& Forage Science 58(3):302-308 DOI: 10.1046/j.1365-2494.2003.00382.x.

Dong WH, Zhang S, Rao X, Liu CA. 2016. Newly-reclaimed alfalfa forage land improved soil properties comparison to farmland in wheat-maize cropping systems at the margins of oases. Ecological Engineering 94:57-64 DOI: 10.1016/j.ecoleng.2016.05.056.

Doran JW, Parkin TB. 1994. Defining and assessing soil quality. SSSA Special Publications 35:3-21. 
457 Edgar RC. 2010. Search and clustering orders of magnitude faster than blast. Bioinformatics 26(19):2460-2461. DOI: 10.1093/bioinformatics/btq461

459

460

461

462

463

464

465

466

467

468

469

470

471

472

473

474

475

476

477

Edgar RC, Haas BJ, Clemente JC, Quince C, Knight R. 2011. UCHIME improves sensitivity and speed of chimera detection. Bioinformatics 27:2194-2200 DOI: 10.1093/bioinformatics/btr381 .

Fan J, Hao M, Malhi SS, Wang Q, Huang M. 2011. Influence of 24 annual applications of fertilisers and/or manure to alfalfa on forage yield and some soil properties under dryland conditions in northern China. Polish Journal of Ecology 59(3):437-443 DOI: 10.1071/CP10370.

Feng T, Wang YY, Zhang YH, Shi XH, Qin CH, Zhang SA, Jin SC, Zhang H, Zhang J. 2016. Effects of wheat and soybean stubbles on soil sickness in continuous cropping of cucumber. Allelopathy Journal 39(1):43-53.

Fu H, Zhang G, Zhang F, Sun Z, Geng G, Li T. 2017. Effects of continuous tomato monoculture on soil microbial properties and enzyme activities in a solar greenhouse. Sustainability 9(2):317 DOI: 10.3390/su9020317.

Guo ZY, Kong CH, Wang JG, Wang YF. 2011. Rhizosphere isoflavones (daidzein and genistein) levels and their relation to the microbial community structure of mono-cropped soybean soil in field and controlled conditions. Soil Biology \& Biochemistry 11:2257-2264 DOI: 10.1016/j.soilbio.2011.07.022.

Han QF, Jia ZK, Wang JP. 2005. The analysis of current situation and development prospect of alfalfa industry at home and abroad. Pratacultural Science, 22(3): 22-25. 
478 Harreither W, Sygmund C, Augustin M, Narciso M, Rabinovich ML, Gorton L, Haltrich D, 479 Ludwig R. 2011. Catalystic properties and classification of cellobiose dehydrogenases from 10.1128/AEM.02052-10.

482

483

484

485

486

487

488

489

490

491

492

493

494

495

496 ascomycetes. Applied and Environmental Microbiology 77:1804-1815 DOI:

Huang X, Liu L, Wen T, Zhang J, Wang F, Cai Z. 2016. Changes in the soil microbial community after reductive soil disinfestation and cucumber seedling cultivation. Applied Microbiology \& Biotechnology 100(12):1-13 DOI: 10.1007/s00253-016-7362-6.

Ismail MA. 2001. Deterioration and spoilage of peanuts and desiccated coconuts from two subSaharan tropical East African countries due to the associated mycobiota and their degradative enzymes. Mycopathologia 150:67-84 DOI: 10.1023/A:1010863507652.

Israel NK, Takashi Y, Keisuke S, Dela CTE. 2018. Antibacterial, cytotoxic and trypanocidal activities of marine-derived fungi isolated from Philippine macroalgae and seagrasses. Acta Botanica Croatica 77(2):141-151 DOI: 10.2478/botcro-2018-0016.

Jiang JP, Xiong YC, Jia Y, Li FM, Xu JZ, Jiang HM. 2007. Soil quality dynamics under successional alfalfa field in the semi-arid loess plateau of northwestern China. Arid Soil Research \& Rehabilitation 21(4):287-303 DOI: 10.1080/15324980701603524.

Jie WG, Liu X, Cai BY. 2013. Diversity of rhizosphere soil arbuscular mycorrhizal fungi in various soybean cultivars under different continuous cropping regimes. PLoS ONE 8(8):e72898 DOI: 10.1371/journal.pone.0072898. 
497 Jones DL, Willett VB. 2006. Experimental evaluation of methods to quantify dissolved organic 498 nitrogen (DON) and dissolved organic carbon (DOC) in soil. Soil Biology and Biochemistry 499 38:991-999 DOI: 10.1016/j.soilbio.2005.08.012.

500 Kluczek-Turpeinen B, Maijala P, Hofrichter M, Hatakka A. 2007. Degradation and enzymatic International Biodeterioration \& Biodegradation 59(4):283-291 DOI: 10.1016/j.ibiod.2006.09.007.

Kong QQ, Ruan L, Liu DX, Liu ZY, Zhang YZ, Qin F, Yuan JH, Ma ZH, Wang HG. 2018. Biological characteristics of Fusarium causing alfalfa root rot in Hebei Province. Journal of China Agricultural University, 23(8): 59-76 (In Chinese).

Li CG, Li XM, Kong WD, Ying W, Wang JG. 2010. Effect of monoculture soybean on soil microbial community in the northeast China. Plant \& Soil 330(1-2):423-433 DOI: 10.1007/s11104-009-0216-6.

Li WC, Li WM, Meng YR. 2005. Biological characteristics of dry root rot (Fusarium solani) of Medicago sativa. Acta Prataculturae Sinica 14(4):106-110 (In Chinese). Loess Plateau of China. Agriculture Ecosystems \& Environment 124:24-32. 
517 Liu J, Sui Y, Yu Z, Shi Y, Chu H, Jin J, Liu X, Wang G. 2015. Soil carbon content drives the

518 biogeographical distribution of fungal communities in the black soil zone of northeast China.

$519 \quad$ Soil Biology \& Biochemistry 83:29-39 DOI: 10.1016/j.soilbio.2015.01.009.

520

521

522

523

524

525

526

527

528

529

530

531

532

533

534

535

536

537

Liu X, Zhang J, Gu T, Zhang W, Shen Q, Yin S, Qiu H. 2014. Microbial community diversities and taxa abundances in soils along a seven-year gradient of potato monoculture using highthroughput pyrosequencing approach. PLoS ONE 9:e86610 DOI: 10.1371/journal.pone.0086610.

Luo CG, Deng YW, Inubushi K, Liang J, Zhu SP, Wei ZY, Guo XB, Luo XP. 2018. Sludge biochar amendment and alfalfa revegetation improve soil physicochemical properties and increase diversity of soil microbes in soils from a rare earth element mining wasteland. International Journal of Environmental Research \& Public Health 15(5): 965 DOI: 10.3390/ijerph15050965.

Lupwayi NZ, Harker KN, Clayton GW, Turkington TK, Rice WA, O'Donovan, J. T. Soil microbial biomass and diversity after herbicide application. Canadian Journal of Plant Science, 2004, 84(2): 677-685.

Lu RK. 1999. Analytical Methods of Soil Agrochemistry. Beijing: Chinese Agriculture Science and Technology Press.

Ma M, Jiang X, Wang Q, Ongena M, Wei D, Ding J, Guan D, Cao F, Zhao B, Li J. 2018. Responses of fungal community composition to long-term chemical and organic fertilization strategies in Chinese Mollisols. MicrobiologyOpen 7(2):e00597 DOI: $10.1002 / \operatorname{mbo} 3.597$. 
538 Mackie JM, Lloyd DL, Ryley MJ, Irwin JAG. 1999. Fungal diseases of temperate annual pasture

539 legumes in southern Queensland. Animal Production Science 39(6):699-707 DOI:

$540 \quad 10.1071 /$ EA99012.

541 Meng TZ, Yang YJ, Cai ZC, Ma Y. 2018. The control of Fusarium oxysporum in soil treated 542 with organic material under anaerobic condition is affected by liming and sulfate content. Biology and Fertility of Soils 54(2):295-307 DOI: 10.1007/s00374-017-1260-7.

544 Miranda KM, Espey MG, Wink DA. 2001. A rapid, simple spectrophotometric method for 545 simultaneous detection of nitrate and nitrite. Nitric Oxide 5:62-71 DOI: 10.1006/niox.2000.0319. 
558

559

560

561

562

563

564

565

566

567

568

569

570

571

572

573

574

575

576

577

578

approaches. Current Opinion in Environmental Sustainability 4(5):529-538 DOI:

10.1016/j.cosust.2012.10.009.

Raiesi F. 2007. The conversion of overgrazed pastures to almond orchards and alfalfa cropping systems may favor microbial indicators of soil quality in Central Iran. Agriculture Ecosystems \& Environment 121:309-318 DOI: 10.1016/j.agee.2006.11.002.

Ranzi C, Camera JN, Deuner CC, Ranzi C, Camera JN, Deuner CC. 2017. Influence of continuous cropping on corn and soybean pathogens. Summa Phytopathol 43(1):14-19 DOI: 10.1590/0100-5405/2150.

Ren XL, Jia ZK, Wan SM, Han QF, Chen XL. 2011. The long-term effects of alfalfa on soil water content in the Loess Plateau of northwest China. African Journal of Biotechnology 10(21):4420-4427.

Ruiu L. 2018. Microbial biopesticides in agroecosystems. Agronomy 8(11):235 DOI: 10.3390/agronomy8110235.

Song X, Pan Y, Li L, Wu X, Wang Y. 2018. Composition and diversity of rhizosphere fungal community in coptis chinensis franch. continuous cropping fields. PLoS ONE 13(3), e0193811 DOI: 10.1371/journal.pone.0193811.

Su YZ. 2007. Soil carbon and nitrogen sequestration following the conversion of crop-land to alfalfa forage land in northwest China. Soil \& Tillage Research 92:181-189 DOI: 10.1016/j.still.2006.03.001.

Tan Y, Cui YS, Li HY, Kuang AX, Li XR, Wei YL, Ji XL. 2017. Rhizospheric soil and root endogenous fungal diversity and composition in response to continuous Panax notoginseng 
cropping practices. Microbiological Research 194:10-19 DOI: 10.1016/j.micres.2016.09.009.

581 Wei W, Xu YL, Li SX, Zhu L, Song J. 2015. Developing suppressive soil for root diseases of 582 10.1080/09064710.2014.992941.

White T, Bruns T, Lee S, Taylor J. 1990. PCR protocols a guide to methods and applications. In:

Xiao XY, Wang MW, Zhu HW, Guo ZH, Han XQ, Zeng P. 2017. Response of soil microbial activities and microbial community structure to vanadium stress. Ecotoxicology \& Environmental Safety 142:200-206 DOI: 10.1016/j.ecoenv.2017.03.047.

Yao H, Jiao X, Wu F. 2006. Effects of continuous cucumber cropping and alternative rotations under protected cultivation on soil microbial community diversity. Plant \& Soil 284:195203 DOI: 10.1007/s11104-006-0023-2.

Yao Q, Liu J, Yu Z, Li Y, Jin J, Liu X, Wang G. 2017. Three years of biochar amendment alterssoil physiochemical properties and fungal community composition in a black soil of northeast China. Soil Biology \& Biochemistry 110:56-67 DOI: 10.1016/j.soilbio.2017.03.005. 
598 Zhang J, Wang Q, Xiao Y, Pang XP, Jia, T. T., Song, R., Liu, H. X. 2016. Effects of alternate 599 furrow irrigation on the biomass allocation and water use efficiency of alfalfa. Acta $600 \quad$ Prataculturae Sinica, 25:164-171 DOI: 10.11686/cyxb2015232.

601 Zhong Y, Wang J, Song Y, Liang Y, Li G. 2012. Microbial community and functional genes in 602 the rhizosphere of alfalfa in crude oil-contaminated soil. Frontiers of Environmental 603 Science \& Engineering 6(6):797-805 DOI: 10.1007/s11783-012-0405-z. 
Figure 1

Phylogenetic relationships of fungal communities shown with the relative abundances of different fungal phyla

$A C C 1 y, A C C 2 y, A C C 6 y, A C C 9 y, A C C 12 y, A C C 13 y$ and $A C C 35 y$ represent the treatments of alfalfa continuous cropping for $1,2,6,9,12,13$ and 35 years, respectively.

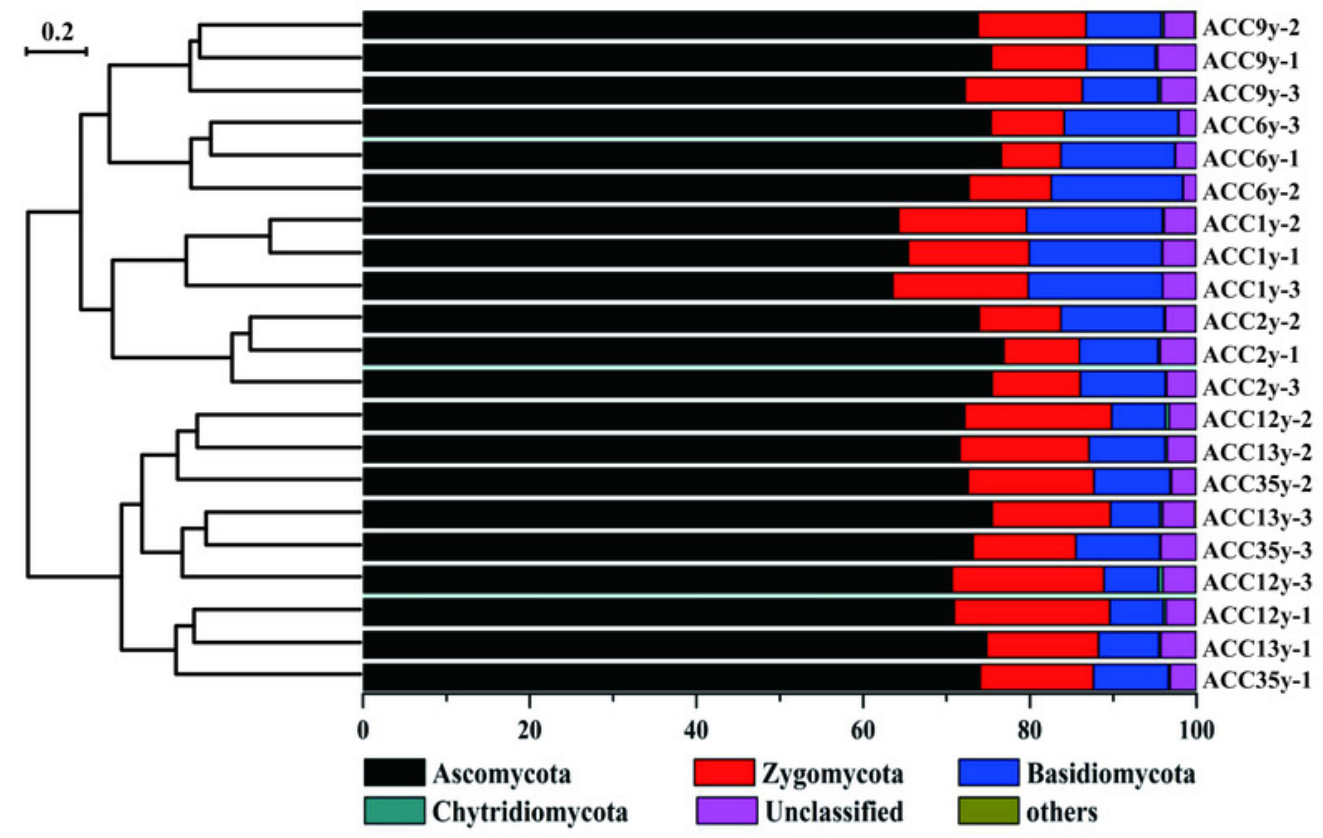


Figure 2

The relationship between relative abundances of dominant fungal genera and alfalfa continuous cropping years
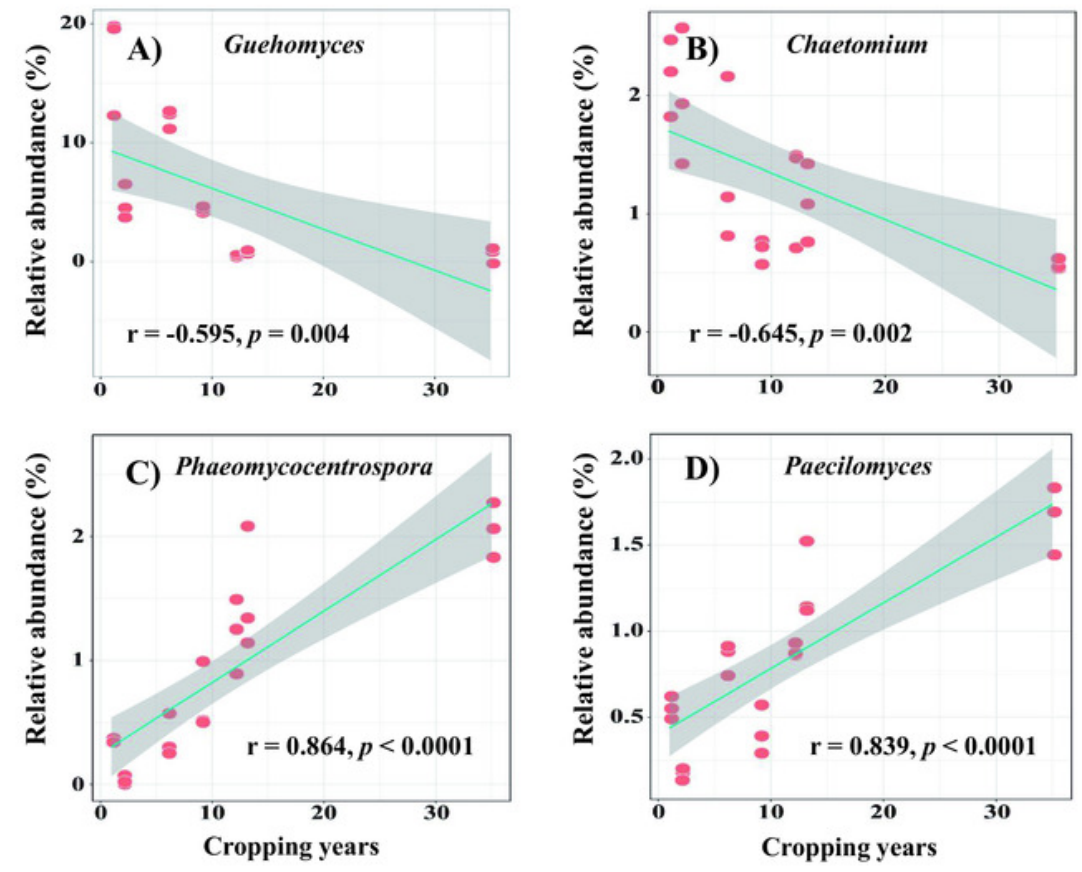


\section{Figure 3}

Variations in composition of fungal functional groups inferred by FUNGuild

ACC1y, ACC2y, ACC6y, ACC9y, ACC12y, ACC13y and ACC35y represent the treatments of alfalfa continuous cropping for $1,2,6,9,12,13$ and 35 years, respectively.

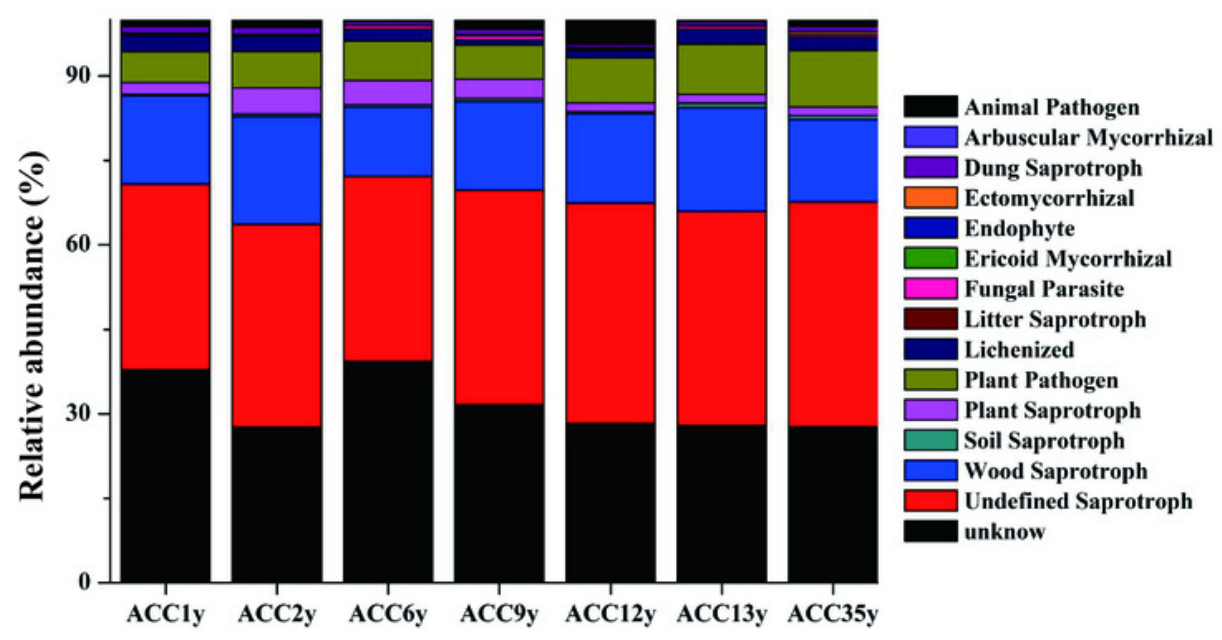


Figure 4 (on next page)

Effect of alfalfa continuous cropping on the relative abundance of dominant plant pathogens at the OTUs level

Different letters above columns indicate significant difference between treatments tested by one-way ANOVA $(P<0.05)$. Error bar show mean $\pm S E(n=3)$. ACC1y, ACC2y, ACC6y, $A C C 9 y, A C C 12 y, A C C 13 y$ and $A C C 35 y$ represent the treatments of alfalfa continuous cropping for $1,2,6,9,12,13$ and 35 years, respectively. 

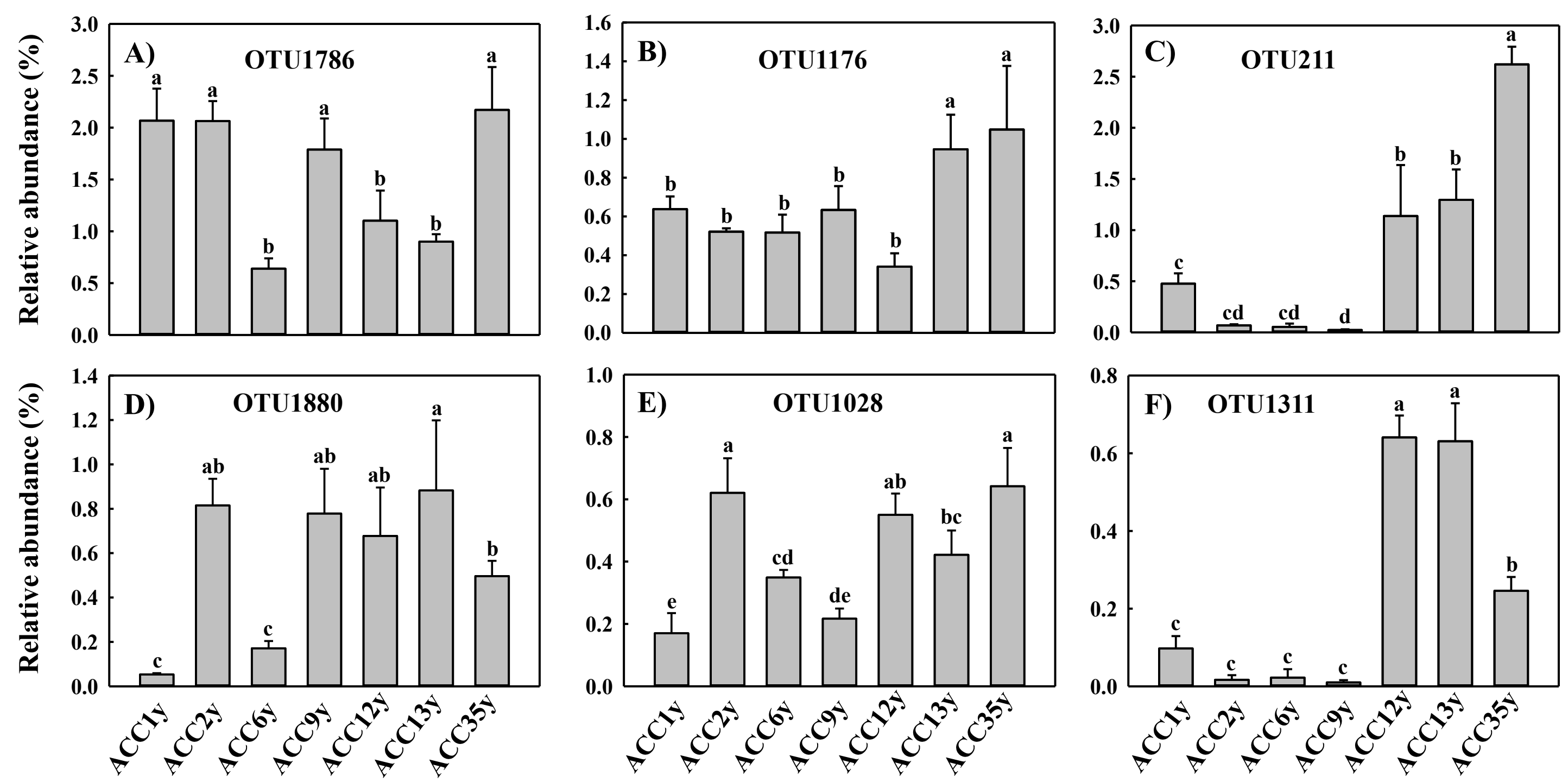
Figure 5

The relationship between soil fungal phylotype richness or phylogenetic diversity and alfalfa continuous cropping year $(A, B)$, soil TP $(C, D)$ or AP $(E, F)$

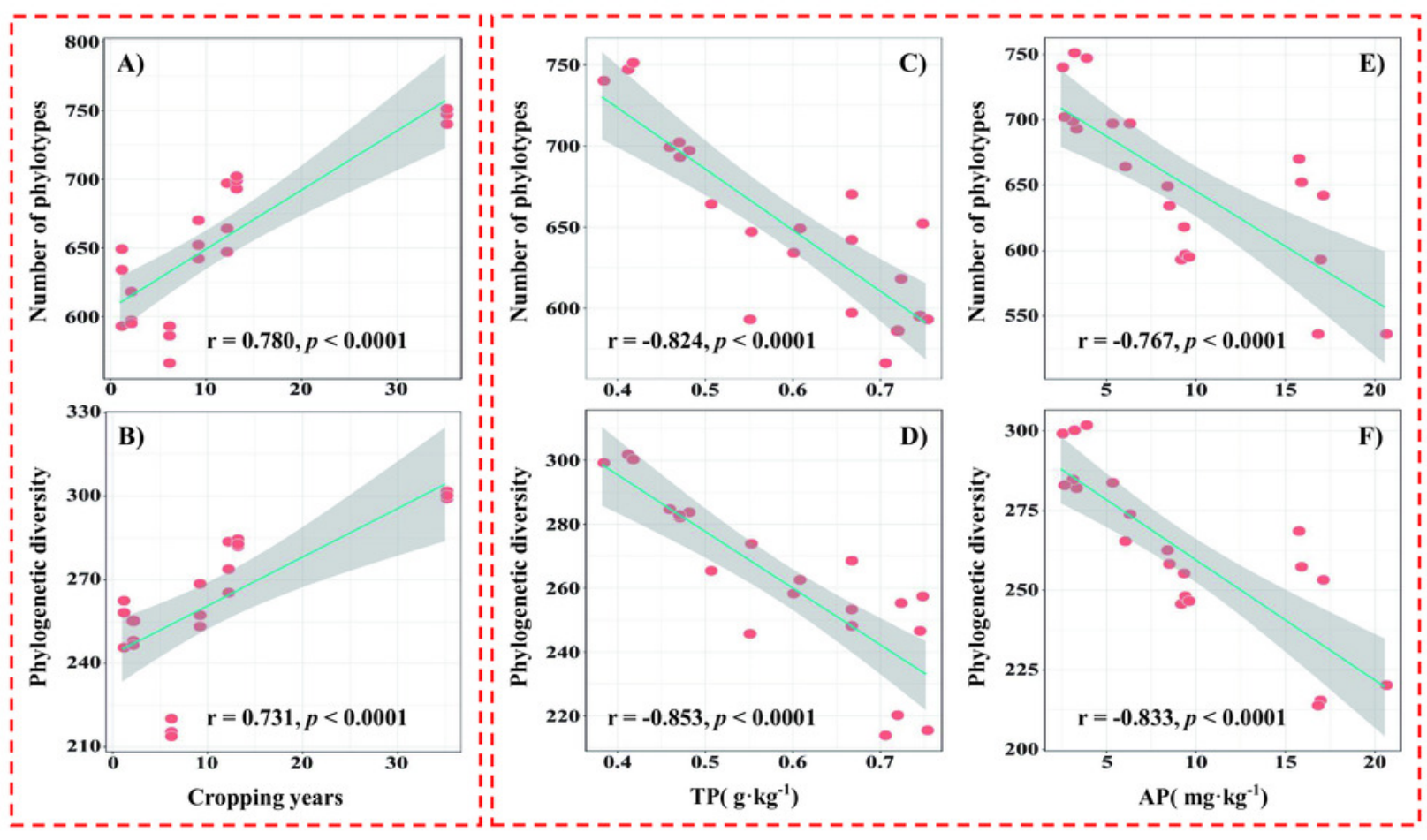


Figure 6 (on next page)

Nonmetric multidimensional scaling (NMDS) plot of soil fungal communities for different continuous cropping treatments (A) and canonical correspondence analysis (CCA) of fungal community changes with soil variables (B)

ACC1y, ACC2y, ACC6y, ACC9y, ACC12y, ACC13y and ACC35y represent the treatments of alfalfa continuous cropping for $1,2,6,9,12,13$ and 35 years, respectively. 

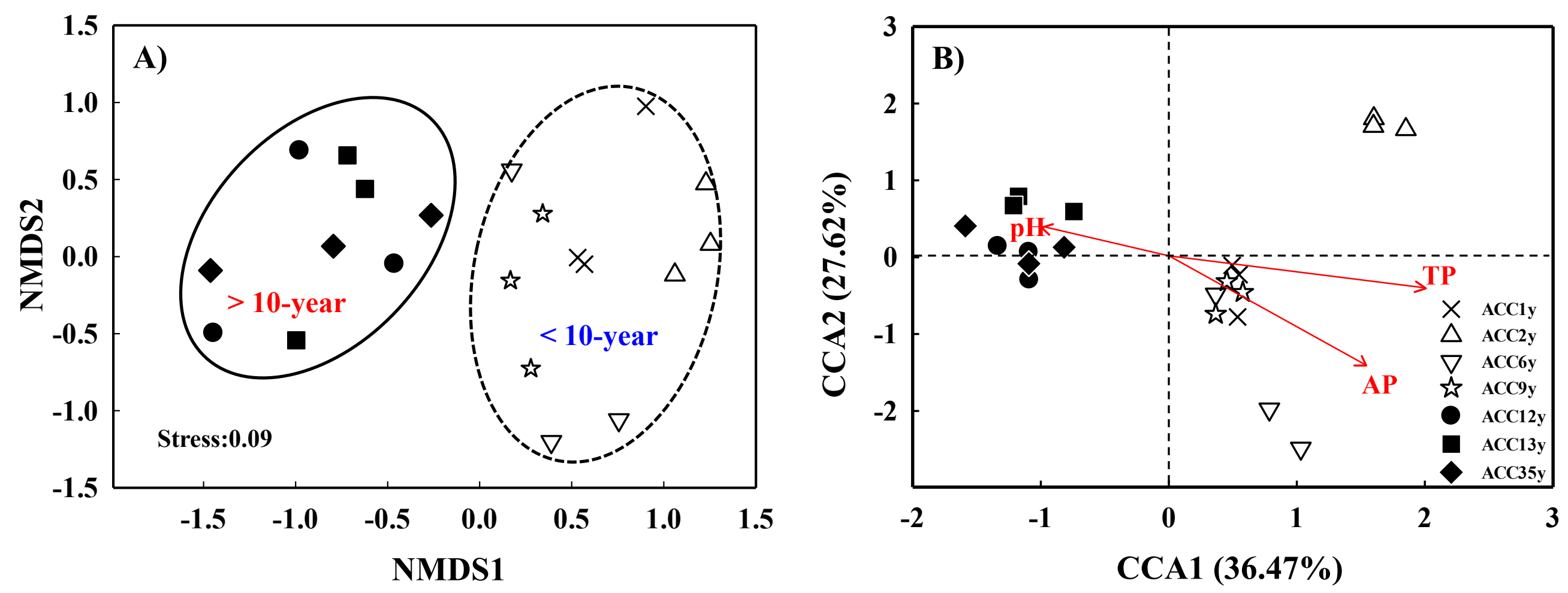


\section{Table 1 (on next page)}

Soil physicochemical properties under alfalfa continuous cropping 
1 Table 1. Soil physicochemical properties under alfalfa continuous cropping

\begin{tabular}{|c|c|c|c|c|c|c|c|c|c|c|}
\hline Treatment & $\mathrm{pH}$ & $\begin{array}{c}\text { Moisture } \\
(\%)\end{array}$ & $\begin{array}{c}\mathrm{TC}^{\mathrm{a}} \\
\left(\mathrm{g} \mathrm{kg}^{-1}\right)\end{array}$ & $\begin{array}{c}\mathrm{TN}^{\mathrm{a}} \\
\left(\mathrm{g} \mathrm{kg}^{-1}\right)\end{array}$ & $\begin{array}{c}\mathrm{TP}^{\mathrm{a}} \\
\left(\mathrm{g} \mathrm{kg}^{-1}\right)\end{array}$ & $\begin{array}{c}\mathrm{TK}^{\mathrm{a}} \\
\left(\mathrm{g} \mathrm{kg}^{-1}\right)\end{array}$ & $\begin{array}{l}\mathrm{NH}_{4}{ }^{+}-\mathrm{N} \\
\left(\mathrm{mg} \mathrm{kg}^{-1}\right)\end{array}$ & $\begin{array}{c}\mathrm{NO}_{3}{ }^{-}-\mathrm{N} \\
\left(\mathrm{mg} \mathrm{kg}^{-1}\right)\end{array}$ & $\begin{array}{c}\mathrm{AP}^{\mathrm{a}} \\
\left(\mathrm{mg} \mathrm{kg}^{-1}\right)\end{array}$ & $\begin{array}{c}\mathrm{AK}^{\mathrm{a}} \\
\left(\mathrm{mg} \mathrm{kg}^{-1}\right)\end{array}$ \\
\hline $\mathrm{ACC} 1 \mathrm{y}^{\mathrm{b}}$ & $8.34 \pm 0.03 c^{c}$ & $15.41 \pm 1.62 \mathrm{ab}$ & $22.52 \pm 0.38 \mathrm{a}$ & $1.20 \pm 0.04 b$ & $0.58 \pm 0.03 b$ & $20.02 \pm 0.22 b c$ & $57.91 \pm 3.21 \mathrm{a}$ & $5.67 \pm 0.46 \mathrm{a}$ & $8.60 \pm 0.42 c$ & $128.34 \pm 5.25 b c$ \\
\hline $\mathrm{ACC} 2 \mathrm{y}$ & $8.43 \pm 0.16 b c$ & $14.41 \pm 0.21 b$ & $19.66 \pm 0.08 b c$ & $1.18 \pm 0.02 b$ & $0.71 \pm 0.04 \mathrm{a}$ & $20.16 \pm 0.46 b c$ & $60.17 \pm 6.28 \mathrm{a}$ & $4.17 \pm 0.11 b c$ & $9.35 \pm 0.15 \mathrm{c}$ & $133.06 \pm 5.40 \mathrm{~b}$ \\
\hline ACC6y & $8.40 \pm 0.05 \mathrm{c}$ & $14.10 \pm 0.85 b c$ & $18.73 \pm 0.62 \mathrm{~cd}$ & $1.19 \pm 0.05 \mathrm{~b}$ & $0.72 \pm 0.02 \mathrm{a}$ & $21.19 \pm 0.76 \mathrm{a}$ & $56.47 \pm 0.96 \mathrm{a}$ & $3.92 \pm 0.12 \mathrm{c}$ & $18.05 \pm 2.17 \mathrm{a}$ & $122.36 \pm 2.68 \mathrm{c}$ \\
\hline ACC9y & $8.60 \pm 0.03 \mathrm{a}$ & $12.73 \pm 0.29 c$ & $17.39 \pm 0.79 \mathrm{~d}$ & $0.83 \pm 0.03 \mathrm{c}$ & $0.69 \pm 0.05 \mathrm{a}$ & $21.46 \pm 0.34 \mathrm{a}$ & $57.51 \pm 1.05 \mathrm{a}$ & $3.93 \pm 0.17 \mathrm{c}$ & $16.16 \pm 0.75 b$ & $103.93 \pm 1.63 \mathrm{~d}$ \\
\hline $\mathrm{ACC} 12 \mathrm{y}$ & $8.54 \pm 0.02 \mathrm{ab}$ & $14.76 \pm 0.77 \mathrm{ab}$ & $24.01 \pm 1.49 \mathrm{a}$ & $1.44 \pm 0.14 \mathrm{a}$ & $0.51 \pm 0.04 \mathrm{c}$ & $19.53 \pm 0.59 \mathrm{c}$ & $56.27 \pm 4.16 \mathrm{a}$ & $4.18 \pm 0.14 b c$ & $5.79 \pm 0.50 \mathrm{~d}$ & $128.58 \pm 6.03 b c$ \\
\hline ACC13y & $8.55 \pm 0.08 \mathrm{ab}$ & $14.81 \pm 0.48 \mathrm{ab}$ & $19.08 \pm 1.26 \mathrm{~cd}$ & $1.34 \pm 0.16 \mathrm{ab}$ & $0.46 \pm 0.01 \mathrm{c}$ & $20.89 \pm 0.02 \mathrm{ab}$ & $55.91 \pm 1.29 \mathrm{a}$ & $5.45 \pm 1.77 \mathrm{ab}$ & $2.92 \pm 0.34 \mathrm{e}$ & $128.05 \pm 0.79 b c$ \\
\hline ACC35y & $8.47 \pm 0.01 \mathrm{abc}$ & $16.26 \pm 0.55 \mathrm{a}$ & $20.88 \pm 1.01 b$ & $1.54 \pm 0.18 \mathrm{a}$ & $0.40 \pm 0.02 \mathrm{~d}$ & $20.78 \pm 0.65 \mathrm{ab}$ & $57.13 \pm 2.36 \mathrm{a}$ & $6.03 \pm 0.81 \mathrm{a}$ & $3.11 \pm 0.67 \mathrm{e}$ & $159.13 \pm 8.35 \mathrm{a}$ \\
\hline
\end{tabular}

2 a TC, TN, TP, TK, AP and AK indicate soil total carbon, total nitrogen, total phosphorus, total potassium, available phosphorus and available potassium, respectively.

3 b ACC1y, ACC2y, ACC6y, ACC9y, ACC12y, ACC13y and ACC35y represent the treatments of alfalfa continuous cropping for 1, 2, 6, 9, 12, 13 and 35 years, respectively.

$4{ }^{\mathrm{c}}$ Different letters within the same column indicate significant difference between treatments tested by One-Way ANOVA $(P<0.05)$. Values are the means \pm SE $(\mathrm{n}=3)$. 


\section{Table 2 (on next page)}

Illumina MiSeq sequenced fungal data and fungal community diversity indices (at $97 \%$ sequence similarity) based on the ITS rRNA gene 
1 Table 2 Illumina MiSeq sequenced fungal data and fungal community diversity indices (at 97\% sequence similarity) based on the ITS

\begin{tabular}{|c|c|c|c|c|c|c|c|}
\hline Treatment & $\begin{array}{l}\text { Fungal } \\
\text { sequences }\end{array}$ & $\begin{array}{l}\text { Number of } \\
\text { phylotype }^{\text {a }}\end{array}$ & $\begin{array}{l}\text { Chao1 } \\
\text { Richness }^{\text {a }}\end{array}$ & $\begin{array}{l}\text { Shannon } \\
\text { index }^{\mathrm{a}}\end{array}$ & $\begin{array}{l}\text { Simpson } \\
\text { index }^{\mathrm{a}}\end{array}$ & $\begin{array}{l}\text { Phylogenetic } \\
\text { diversity }^{\mathrm{a}}\end{array}$ & $\begin{array}{l}\text { Coverage } \\
(\%)^{\mathrm{a}}\end{array}$ \\
\hline ACCly ${ }^{b}$ & $36757 \pm 5250^{c}$ & $625 \pm 29 \mathrm{de}^{\mathrm{d}}$ & $837 \pm 21 \mathrm{a}$ & $4.40 \pm 0.05 \mathrm{~d}$ & $0.030 \pm 0.003 \mathrm{a}$ & $255.41 \pm 8.76 \mathrm{c}$ & 99.42 \\
\hline $\mathrm{ACC} 2 \mathrm{y}$ & $37751 \pm 3436$ & $603 \pm 13 e$ & $770 \pm 28 b c$ & $4.56 \pm 0.07 \mathrm{c}$ & $0.020 \pm 0.002 b$ & $249.91 \pm 4.63 c$ & 99.47 \\
\hline ACC6y & $41112 \pm 1377$ & $555 \pm 33 \mathrm{f}$ & $689 \pm 34 d$ & $4.17 \pm 0.06 \mathrm{e}$ & $0.027 \pm 0.005 \mathrm{a}$ & $216.41 \pm 3.31 d$ & 99.49 \\
\hline ACC9y & $38180 \pm 7604$ & $655 \pm 14 \mathrm{~cd}$ & $749 \pm 42 \mathrm{c}$ & $4.69 \pm 0.14 \mathrm{bc}$ & $0.018 \pm 0.000 \mathrm{~b}$ & $259.63 \pm 7.93 \mathrm{c}$ & 99.51 \\
\hline $\mathrm{ACC} 12 \mathrm{y}$ & $36652 \pm 2427$ & $686 \pm 19 b c$ & $814 \pm 11 \mathrm{ab}$ & $4.62 \pm 0.08 b c$ & $0.022 \pm 0.000 \mathrm{~b}$ & $274.23 \pm 9.17 b$ & 99.49 \\
\hline ACC13y & $37392 \pm 5169$ & $698 \pm 5 b$ & $860 \pm 31 \mathrm{a}$ & $4.74 \pm 0.07 \mathrm{ab}$ & $0.019 \pm 0.000 \mathrm{~b}$ & $283.13 \pm 1.32 b$ & 99.43 \\
\hline ACC $35 y$ & $36402 \pm 5219$ & $746 \pm 6 \mathrm{a}$ & $845 \pm 40 \mathrm{a}$ & $4.84 \pm 0.04 \mathrm{a}$ & $0.019 \pm 0.003 b$ & $300.31 \pm 1.31 \mathrm{a}$ & 99.43 \\
\hline
\end{tabular}

3 a Those data were calculated from 29000 fungal sequences per soil sample.

4 b ACC1y, ACC2y, ACC6y, ACC9y, ACC12y, ACC13y and ACC35y represent the treatments of alfalfa continuous cropping for 1, 2, 6, 9, 12, 13 and 35 years, respectively.

$5 \mathrm{c}$ Values are the means $\pm \mathrm{SE}(\mathrm{n}=3)$.

6 d Different letters within the same column indicate significant difference between treatments tested by One-Way ANOVA $(P<0.05)$. 